\title{
Tropospheric observations of CFC-114 and CFC-114a with a focus on long-term trends and emissions
}

\author{
Johannes C. Laube ${ }^{1}$, Norfazrin Mohd Hanif ${ }^{1}$, Patricia Martinerie ${ }^{2}$, Eileen Gallacher ${ }^{1}$, Paul J. Fraser ${ }^{3}$, \\ Ray Langenfelds ${ }^{3}$, Carl A. M. Brenninkmeijer ${ }^{4}$, Jakob Schwander ${ }^{5}$, Emmanuel Witrant ${ }^{6}$, Jia-Lin Wang ${ }^{7}$, \\ Chang-Feng Ou-Yang ${ }^{8}$, Lauren J. Gooch ${ }^{1}$, Claire E. Reeves ${ }^{1}$, William T. Sturges ${ }^{1}$, and David E. Oram ${ }^{1,9}$ \\ ${ }^{1}$ Centre for Ocean and Atmospheric Sciences, School of Environmental Sciences, University of East Anglia, \\ Norwich, NR4 7TJ, UK \\ ${ }^{2}$ UJF-Grenoble 1/CNRS, Laboratoire de Glaciologie et Géophysique de l'Environnement, 38041, Grenoble, France \\ ${ }^{3}$ Oceans and Atmosphere, Commonwealth Scientific and Industrial Research Organisation, Aspendale, Australia \\ ${ }^{4}$ Air Chemistry Division, Max Planck Institute for Chemistry, Mainz, Germany \\ ${ }^{5}$ Physics Institute, University of Berne, Bern, Switzerland \\ ${ }^{6}$ UJF-Grenoble 1/CNRS, Grenoble Image Parole Signal Automatique, Grenoble, France \\ ${ }^{7}$ Department of Chemistry, National Central University, Zhongli, Taiwan \\ ${ }^{8}$ Department of Atmospheric Sciences, National Central University, Taipei, Taiwan \\ ${ }^{9}$ National Centre for Atmospheric Science, School of Environmental Sciences, University of East Anglia, \\ Norwich, NR4 7TJ, UK
}

Correspondence to: Johannes C. Laube (j.laube@uea.ac.uk)

Received: 11 July 2016 - Published in Atmos. Chem. Phys. Discuss.: 2 August 2016

Revised: 9 November 2016 - Accepted: 23 November 2016 - Published: 9 December 2016

\begin{abstract}
Chlorofluorocarbons (CFCs) are ozone-depleting substances as well as strong greenhouse gases, and the control of their production and use under the Montreal Protocol has had demonstrable benefits to both mitigation of increasing surface UV radiation and climate forcing. A global ban on consumption came into force in 2010, but there is evidence of continuing emissions of certain $\mathrm{CFCs}$ from a range of sources. One compound has received little attention in the literature, namely CFC-114 $\left(\mathrm{C}_{2} \mathrm{Cl}_{2} \mathrm{~F}_{4}\right)$. Of particular interest here is the differentiation between $\mathrm{CFC}-114\left(\mathrm{CClF}_{2} \mathrm{CClF}_{2}\right)$ and its asymmetric isomeric form $\mathrm{CFC}-114 \mathrm{a}\left(\mathrm{CF}_{3} \mathrm{CCl}_{2} \mathrm{~F}\right)$ as atmospheric long-term measurements in the peer-reviewed literature to date have been assumed to represent the sum of both isomers with a time-invariant isomeric speciation. Here we report the first long-term measurements of the two isomeric forms separately, and find that they have different origins and trends in the atmosphere.

Air samples collected at Cape Grim $\left(41^{\circ} \mathrm{S}\right)$, Australia, during atmospheric background conditions since 1978, combined with samples collected from deep polar snow (firn) enable us to obtain a near-complete record of both gases since
\end{abstract}

their initial production and release in the 1940s. Both isomers were present in the unpolluted atmosphere in comparably small amounts before 1960 . The mixing ratio of CFC114 doubled from 7.9 to 14.8 parts per trillion (ppt) between the start of the Cape Grim record in 1978 and the end of our record in 2014, while over the same time CFC-114a trebled from 0.35 to 1.03 ppt. Mixing ratios of both isomers are slowly decreasing by the end of this period. This is consistent with measurements of recent aircraft-based samples showing no significant interhemispheric mixing ratio gradient.

We also find that the fraction of CFC-114a mixing ratio relative to that of CFC-114 increased from 4.2 to $6.9 \%$ over the 37-year period. This contradicts the current tacit assumption used in international climate change and ozone depletion assessments that both isomers have been largely co-emitted and that their atmospheric concentration ratio has remained approximately constant in time. Complementary observations of air collected in Taiwan indicate a persisting source of CFC-114a in South East Asia which may have been contributing to the changing balance between the two isomers. 
In addition we present top-down global annual emission estimates of CFC-114 and CFC-114a derived from these measurements using a two-dimensional atmospheric chemistry-transport model. In general, the emissions for both compounds grew steadily during the 1980 s, followed by a substantial reduction from the late 1980s onwards, which is consistent with the reduction of emission in response to the Montreal Protocol, and broadly consistent with bottom-up estimates derived by industry. However, we find that small but significant emissions of both isomers remain in 2014 . Moreover the inferred changes to the ratio of emissions of the two isomers since the 1990s also indicate that the sources of the two gases are, in part, independent.

\section{Introduction}

Chlorofluorocarbons (CFCs) are halogenated hydrocarbons of exclusively anthropogenic origin. These relatively inert gases have been widely used in a variety of applications (e.g. as refrigerants, propellants and foam-blowing agents) since the 1930s. CFCs tend to persist in the atmosphere due to the absence of a significant tropospheric sink process. They eventually are broken down in the stratosphere thereby releasing reactive chlorine, which catalytically destroys ozone (Rowland and Molina, 1975), resulting in increases in harmful UV radiation at the surface. Since the discovery of the Antarctic ozone hole (Farman et al., 1985), the enforcement and subsequent amendments of the Montreal Protocol on Substances that Deplete the Ozone Layer (1989) have resulted in the successful phase-out of CFC production and consumption in industrialised and developing nations by 2010 (apart from relatively minor critical-use exemptions). Consequently, the abundance of most documented CFCs in the atmosphere started to decline (Montzka et al., 1996a, 2010; Rigby et al., 2013; Carpenter et al., 2014; Laube et al., 2014; for Montreal Protocol ratification status see UNEP, 2014).

Continued research and monitoring of all ozone-depleting substances (ODSs) are essential to ensure compliance with the Montreal Protocol for environmental protection against ozone loss.

This study focuses on two CFC compounds that have been particularly understudied to date. The isomeric pair of CFC$114\left(\mathrm{CClF}_{2} \mathrm{CClF}_{2}\right)$ and asymmetric CFC-114a $\left(\mathrm{CF}_{3} \mathrm{CCl}_{2} \mathrm{~F}\right)$ were primarily used as aerosol propellants, as blowing agents in polyolefin foams and as refrigerants in long-lived appliances (Fisher and Midgley, 1993) before production was banned following the Montreal Protocol (UNEP, 2014). Minor remaining uses of CFC-114 were for cooling processes, e.g. in naval vessels (Andersen et al., 2007). CFC-114a has also been reportedly used in the production of HFC-134a, the latter being one of the alternatives to replace CFC-114 used in chillers (Banks et al., 1994). The Alternative Fluorocar- bons Environmental Acceptability Study (AFEAS) reported that $514319 \mathrm{t}$ of the isomers (combined) was produced between 1937 and 2004, primarily in the Northern Hemisphere, $\sim 15 \%$ of which was used within long-lived applications ( $>12$ years lifetime), providing a substantial bank of the isomers to potentially produce continued emissions to the atmosphere (AFEAS, 1995, 2009).

As with all CFCs, the stratospheric loss processes of these isomers are photolysis by ultraviolet radiation and reaction with excited-state atomic oxygen $\left(\mathrm{O}\left({ }^{1} \mathrm{D}\right)\right.$ - a product of ozone photolysis). The dominant loss process for CFC-114 is the former, with the latter thought to be responsible for $25 \%$ of its total stratospheric loss. The reaction of CFC-114a with $\mathrm{O}\left({ }^{1} \mathrm{D}\right)$ is thought to be faster than that of CFC-114. In addition, CFC-114a is more susceptible to photolysis than CFC114 , resulting in the CFC-114a atmospheric lifetime being shorter than that of CFC-114 (Burkholder et al., 2013; Davis et al., 2016). The total atmospheric steady-state lifetimes of CFC-114 and CFC-114a are currently estimated to be $\sim 189$ and $\sim 100$ years respectively (Burkholder et al., 2013; Carpenter et al., 2014; Davis et al., 2016).

CFC-114 and CFC-114a are difficult to separate as their boiling points are almost identical. The similarity of their mass spectra complicates even their separate detection with mass spectrometric techniques. Therefore, their abundance is usually reported as a sum of both isomers, assuming a fraction of $\sim 10 \%$ of CFC-114a (Carpenter et al., 2014).

Two previous studies reconstructed historical trends for CFC-114 or the sum of CFC-114 and CFC-114a using firn air data (Sturrock et al., 2002; Martinerie et al., 2009). Sturrock et al. (2002) used inverse firn modelling techniques constrained with firn air data from an Antarctic site (Law Dome) and air archive data from an observatory at Cape Grim, Australia $\left(40.7^{\circ} \mathrm{S}, 144.7^{\circ} \mathrm{E}\right.$; Oram, 1999), to reconstruct a CFC-114+CFC-114a atmospheric trend, and concluded that southern hemispheric concentrations were negligible before 1960. Their firn air-based data (calibration first reported in Prinn et al., 2000) were compared with University of East Anglia (UEA) data of CFC-114 (fully separated from CFC-114a) from Cape Grim on an earlier UEA calibration scale (Lee, 1994) and a calibration difference (factor of 0.94 , constant over time) was found. Martinerie et al. (2009) used AFEAS emissions and an atmospheric chemistry model to calculate atmospheric trends that were compared to firn data at five sites from Antarctica and Greenland using a forward firn modelling approach. They concluded that the AFEAS-emissions-based trend, leading to significant atmospheric concentrations before 1960 , is inconsistent with the firn and atmospheric data-based trend from Sturrock et al. (2002) and that the Sturrock et al. (2002) trend is more consistent with their northern hemispheric firn data than the AFEAS-based trend. The firn data used in Martinerie et al. (2009) are a combination of UEA CFC-114 measurements at North GRIP, Berkner Island and Dome C (earlier calibration scale) and NCAR CFC-114 + CFC-114a 
measurements at Devon Island, North GRIP and Dronning Maud Land.

In addition to early attempts of quantification (e.g. Chen et al., 1994) and the regular global mixing ratio updates in recent WMO ozone assessments, Reimann et al. (2004) reported atmospheric CFC-114 abundances having stabilised with elevated levels essentially absent in the latest part of the record from the high-altitude station at Jungfraujoch, Switzerland. Moreover, the study of Chan et al. (2006) found no substantial emissions from the heavily industrialised region in the Pearl River delta in China. Again, none of these studies distinguishes between the two isomeric forms of CFC-114. We here provide, for the first time, a complete quantification of both isomers, based on an analysis of a combination of archived remote southern hemispheric tropospheric air and firn air data that allows the reconstruction of a tropospheric record from 1960 to 2014. The abundances, temporal evolution and emissions of both isomers are evaluated using measurement and modelling techniques that have been updated and improved since the first measurements in the 1990s (Lee, 1994; Oram, 1999). Further insights are derived from aircraft-based observations as well as samples collected in East Asia.

\section{Methodology}

\subsection{Sample collection}

Air samples are routinely collected at Cape Grim for measurement and archiving during baseline conditions (clean marine air, wind speeds $>15 \mathrm{~km} \mathrm{~h}^{-1}$ and direction $190-290^{\circ}$; Fraser et al., 1999) representing unpolluted southern hemispheric air with long air mass back-trajectories over the Southern Ocean, distant from pollution sources prior to their arrival at Cape Grim. UEA stores an archive of such air samples currently spanning 1978-2014. We have analysed 117 of these archived samples. All samples collected before 1994 were subsamples of the parent Cape Grim air archive, transferred to and stored in 3 L electropolished stainless steel canisters. Post 1994 the majority of samples have been collected in situ into $3 \mathrm{~L}$ stainless steel canisters (either electrochemically passivated or Silco-treated (Restek Corp.), e.g. Sturges, et al., 2012) to $\sim 3$ bar, using a metal bellows pump, with the remainder being subsamples of the parent archive. Several studies have shown that mixing ratios of many species within the parent CSIRO Archive or UEA subarchive are similar to in situ measurements made at Cape Grim at or close to the time of the archive sampling - therefore verifying this archive as representative of actual background air and allowing storage of these samples without substantial alterations of concentrations within the samples (e.g. Fraser et al., 1986; Vollmer et al., 2011; Oram et al., 2012; Laube et al., 2013).
In addition, 39 air samples extracted from deep firn snow during two Antarctic drilling campaigns (Berkner Island and Dome $\mathrm{C}$ ) enabled the reconstruction of atmospheric histories of the two gases from dates preceding the start of the Cape Grim record. The firn air extraction procedure and the characteristics of the drilling sites are described in Martinerie et al. (2009).

Also, 15 upper tropospheric samples collected by the CARIBIC Observatory (http://www.caribic-atmospheric. com) on flights between Germany and South Africa on 10 and 11 February 2015 were analysed to assess current interhemispheric mixing ratio gradients and their consistency with the inferred tropospheric records. For details on the sampling system please refer to Brenninkmeijer et al. (2007). We also include results from 23 air samples collected in the important East Asian source region during a groundbased campaign in Taiwan from the Hengchun site $\left(22.1^{\circ} \mathrm{N}\right.$, 120.7 ${ }^{\circ}$ E; 7 m a.s.1.) in March and April 2015.

\subsection{Analytical technique}

Samples were analysed for CFC-114 and CFC-114a by cryogenic trapping followed by gas chromatographic separation and mass spectrometric detection (GC-MS). The GC-MS method is very similar to that described in detail in Laube et al. (2013). Briefly, samples were dried by passing through a magnesium perchlorate $\left(\mathrm{Mg}\left(\mathrm{ClO}_{4}\right)_{2}\right)$ drying tube. Condensable trace gases were subsequently trapped in a packed stainless steel sample loop submerged in a cold bath held at $-78^{\circ} \mathrm{C}$. The sample loop was filled with HayeSep D adsorbent giving quantitative retention and release. The sample loop was heated to near $100^{\circ} \mathrm{C}$ to ensure immediate and complete desorption of the analytes. Some of the samples were analysed on an older but very similar GC-MS system (Oram, 1999; Fraser et al., 1999; Oram et al., 2012; further details in Sect. 3.3).

Separation was carried out using an Agilent 6890 Gas Chromatograph. For full separation of the CFC isomers, a porous-layer open-tubular (PLOT) GC column was used (supplier: Agilent, length: $50 \mathrm{~m}$, ID: $0.32 \mathrm{~mm}$, film thickness: $5 \mu \mathrm{m})$, with aluminium oxide $\left(\mathrm{Al}_{2} \mathrm{O}_{3}\right)$ as the stationary phase, deactivated by potassium chloride $(\mathrm{KCl})$. This deviates significantly from the method described in Laube et al. (2013) and is the crucial detail of the methodology within this study, as this type of GC column does separate CFC114a from CFC-114. The two isomers are primarily separated as a function of their polarities, rather than their boiling points. The GC column was held at $-10^{\circ} \mathrm{C}$ for 2 min and then heated to $180{ }^{\circ} \mathrm{C}$ at $10^{\circ} \mathrm{C} \mathrm{min}^{-1}$ while maintaining a flow rate of $2 \mathrm{~mL} \mathrm{~min}^{-1}$.

The GC is connected to a high-sensitivity trisector (EBE) mass spectrometer (MS) (Micromass/Waters Autospec), which has a typical detection limit $<0.1$ fmole per mole of air $\left(10^{-16}\right)$ when extracting from $300 \mathrm{~mL}$ of air, and was operated in electron impact selected ion recording (EI-SIR) 
mode, and at a mass resolution of $\sim 1000$ at $5 \%$ peak height. CFC-114 and CFC-114a were measured using mass fragments $\mathrm{C}_{2} \mathrm{~F}_{4}^{35} \mathrm{Cl}^{+}$and $\mathrm{C}_{2} \mathrm{~F}_{4}^{37} \mathrm{Cl}^{+}(\mathrm{m} / z, 134.96$ and 136.96). The retention times were 16.69 and 16.87 minutes for CFC114 and CFC-114a respectively. A pure, research-grade helium sample ("blank") was measured on each day and no system contamination was observed of relevance to the analysis of the two compounds. During analysis all samples were bracketed by a "working standard" (clean northern hemispheric air, collected in 2006) after every two to three samples. Measurement uncertainties were calculated as the square root of the sum of the squares of the $1 \sigma$ standard deviations of sample and standard measurements. The average precision was $1.1 \%$ for both isomers.

The detector response was evaluated with regard to its linearity using the same methodology as in Laube et al. (2014), i.e. using a static dilution series prepared from a background air sample collected in 2009 at Niwot Ridge near Boulder, USA (containing $15.2 \mathrm{ppt}$ of CFC-114, and 1.03 ppt of CFC$114 \mathrm{a}$, see Sect. 3.3 for calibration), with pure nitrogen in stainless steel canisters. The six dilutions were 100, 67, 30, 15,7 and $0 \%$ and we found linearity within $1.9 \%$, which is well within the uncertainties of the dilution factors and measurement uncertainties (less than $5 \%$ in all cases).

\subsection{Calibration}

Calibration scales were established for CFC-114 and CFC114a by a two-step dilution process described in Laube et al. (2010) which was improved later (Laube et al., 2012). A pure sample of a mixture of both isomers (5.7\% CFC-114a) was provided by DuPont. This isomeric ratio was determined by gas chromatography with flame ionisation detection (GCFID) at DuPont. The sample was provided at $>99.8 \%$ purity (weight) and contained small amounts of other trace gases, most notably $0.112 \%$ of CFC- 115 and $0.028 \%$ of CFC- 13 . The latter were successfully removed to below detection limits through transfer into a vacuum-tight canister followed by repeated freezing and evacuating cycles. The calibration sample was then diluted into $99.7 \mathrm{~L}$ aluminium drums to near-atmospheric levels (CFC-114: 120 to 160 parts per trillion (ppt); CFC-114a: 6 to 9 ppt) in oxygen-free nitrogen. We here report one particular improvement as compared to the previously reported calibration system, i.e. the improved leak rate of these drums which was achieved through extensive leak-testing and the use of epoxy resin. Observed internal levels of outside air have been reduced to below $0.01 \%$, thus rendering previously required corrections unnecessary. The dilution drums were flushed with $>20000 \mathrm{~L}$ of nitrogen and no major additional organic compounds were detected in the subsequent blanks. The dilutions were analysed by GC-MS (described above and in Laube et al., 2010) and used to assign mixing ratios to the above-mentioned internal reference standard provided by NOAA (used as the working standard). The same dilutions were also analysed in full scan mode to ensure their purity. A CFC for which an independent an internationally recognised calibration exists (CFC-12: diluted to between 260 and $290 \mathrm{ppt}$ ) was added to the dilution drums to assess accuracy of the calibrations by comparing calculated mixing ratios to NOAA calibration values. The three separate calibration analyses were accurate to within $2.4 \%$ of NOAA values (using CFC-12 mixing ratios, 2006 NOAA scale), and we therefore consider the accuracy of the calibration to be $2.4 \%$ at the most. As for the calibration precision the $1 \sigma$ standard deviation of these calibrations was $1.2 \%$ (CFC-114) and $1.5 \%$ (CFC-114a) respectively. Determined mixing ratios are expressed on a volumetric dilution scale, which is not equivalent to a mole (mass)-based scale (e.g. as used by NOAA) unless ideal gas behaviour is assumed. The resultant calibration error in assuming equivalence to a molar (mass) scale has however been proven to be negligible for this particular calibration system (Laube et al., 2010). It should also be noted that the accuracy of our calibration is limited by the accuracy of the ratio of CFC-114 and CFC114a in the sample provided by DuPont, which is unknown. It is however well known that the molar response factors of isomeric compounds are very similar in flame ionisation detectors (e.g. Tong and Karasek, 1984), so this is unlikely to be a major limitation of this study.

These new calibrations were also applied to existing data from firn air (only CFC-114 published in Martinerie et al., 2009) as well as the earlier part of the Cape Grim record (Oram, 1999). Both of these data sets originate from measurements on a previous version of the GC-MS system with the same type of GC column (which has long been known to separate the two isomers) and also using different air standards. Older data had to be transferred to the new calibration scales ("UEA-2014") using repeatedly measured ratios between internal standards. The conversion factor from the old UEA calibration scale (Lee, 1994; Oram, 1999) as published in Martinerie et al. (2009) was determined as 0.9185 for CFC-114 (CFC-114a: 0.5808). To ensure comparability of the data sets, 14 Cape Grim samples collected between 1978 and 2004 have been analysed on both systems and these data agree within uncertainties for both isomers and show no indication for any systematic offset. We therefore conclude that all presented data sets are comparable and can be combined.

\subsection{Firn modelling}

Forward models of gas transport in firn (e.g. Buizert et al., 2012) use an atmospheric mixing ratio trend as input and predict a concentration profile versus depth in firn, which results from gas transport processes in firn such as molecular diffusion, gravitational setting, wind-driven convection etc. Here we use an improved version of the firn model used in Martinerie et al. (2009). A major upgrade is the use of a firn diffusivity profile which optimally fits data from several reference gases with well-known atmospheric histories in the 
firn (Witrant et al., 2012). This model performed well in an international inter-comparison study (Buizert et al., 2012). Two species-dependent physical constants are used in the model: molecular mass and diffusion coefficient in air. We used measured values of the CFC-114 diffusion coefficient from Matsunaga et al. (1993). To our knowledge, no measurement is available for CFC-114a, but the estimation methods commonly used in firn models (Fuller et al., 1966; Chen and Othmer, 1962; Marsh et al., 2007) provide the same diffusion coefficient for CFC-114 and CFC-114a within uncertainties, which we therefore use here.

Inverse models of gas transport in firn use mixing ratio measurements in firn as input and predict atmospheric trends. Such an inverse approach was applied to CFC-114 by Sturrock et al. (2002). Here we use a recently improved inverse model (Rommelaere et al., 1997; Witrant and Martinerie, 2013) which can be constrained by several firn air sampling sites at the same time. The firn model improvements combined with the optimal inverse fit of the data lead to a much better agreement (Fig. S1 in the Supplement) between the calculated atmospheric trend and firn data than in Martinerie et al. (2009). On the other hand, it does not allow an evaluation of the consistency of firn data with emission-based trends. In order to discuss the CFC-114 and CFC-114a budgets, we use an inverse (or top-down) atmospheric modelling approach to infer emissions from atmospheric concentrations (see next section) rather than the forward atmospheric modelling approach in Martinerie et al. (2009).

\subsection{Emission modelling}

The top-down global annual emissions estimates of the CFC114 and CFC-114a were derived using a two-dimensional atmospheric chemistry-transport model. The model comprises of grid boxes which have been equally divided into 24 equalarea, zonally averaged bands and has 12 vertical layers of $2 \mathrm{~km}$ depth. The latitudinal distribution of emissions is based on the assumption that $95 \%$ of emissions originate from industrial activities in the Northern Hemisphere, predominantly from mid-latitudes (in agreement with the work by McCulloch et al., 1994). By using these preferred latitudinal distributions, the transport scheme of the model has been shown to reproduce the reported global distributions of CFC11 and CFC-12 to within 5\% (Reeves et al., 2005).

For the photolysis of CFC-114, the absorption cross sections are calculated for each grid box as a function of seasonally varying temperature for the wavelengths $200-220 \mathrm{~nm}$ (Simon et al., 1988). A log-linear extrapolation of the Simon et al. (1988) data, $\log \sigma(\lambda)=-1.8233-0.0913 \lambda$ was used to derive the absorption cross sections for longer wavelengths in the range of 222-235 nm (Sander et al., 2011). For CFC-114a the absorption data from Davis et al. (2016) were used. The rate coefficients of $1.43 \times 10^{-10}$ and $1.62 \times$ $10^{-10} \mathrm{~cm}^{3}$ molecule $\mathrm{s}^{-1}$ are applied to the reactions of $\mathrm{O}\left({ }^{1} \mathrm{D}\right)$ with $\mathrm{CFC}-114$ and $\mathrm{CFC}-114 \mathrm{a}$, based on work by
Baasandorj et al. (2013) and Baasandorj et al. (2011), respectively. The diffusive loss from the top of the model was set by adjusting the mixing ratio of our studied compounds at $25 \mathrm{~km}$ (i.e. the boundary conditions) such that they were a fraction $(F)$ of those in the top model box $(23 \mathrm{~km})$ (Newland et al., 2013). We use values of 0.922 and 0.837 for $F$ in order to achieve the steady-state lifetime of 189 and 102 years for CFC-114 and CFC-114a, respectively, based on the estimates recently been reported in SPARC (2013) and Carpenter et al. (2014). This is in agreement with the very recently reported lifetime of 105.3 years for CFC-114a, which took into account new UV absorption data (Davis et al., 2016). It should be noted that the vast majority of the loss of both CFC-114 and CFC-114a occurs above the height of the model domain so their modelled lifetimes are largely controlled by the values assigned to $F$, which is adjusted to give the reported atmospheric lifetimes. Once the model had been set up with the above conditions, the emissions in the model were iteratively adjusted (Newland et al., 2013) until the predicted concentrations matched the Cape Grim air measurements from 1978 to 2014. The same approach was also applied using the southern hemispheric firn air-derived trends from 1960 to 2003.

The determination of uncertainty ranges of the emission estimates of CFC-114 and CFC-114a was based on the combination the average measurement uncertainty $(1.1 \%)$, the modelling uncertainty $(5 \%)$ and the model fit uncertainty $(1.1 \%)$ (combined as the square root of the sum of squares of individual uncertainties). Then the calibration uncertainty $(2.4 \%)$ was added to this to give an overall uncertainty. The calculated uncertainty ranges $( \pm 7.6 \%)$ were added to the "best fit" modelled mixing ratios for Cape Grim to derive an envelope of upper and lower uncertainty bounds. The model was then rerun to fit to the upper bound of this envelope using the lower estimate of the lifetime to give the maximum emissions and similarly rerun to fit to the lower bound of the envelope using the upper estimate of the lifetime to give the minimum emissions (following the methodology of Kloss et al., 2014). The range of lifetimes used was 153-247 years for CFC-114 (SPARC, 2013; Carpenter et al., 2014) and a similar relative range of lifetimes (82-133 years) was assumed for CFC-114a.

\section{Results and discussion}

\subsection{Tropospheric long-term trends from firn air and the Cape Grim archive}

The temporal evolution of CFC-114 and CFC-114a is shown in Fig. 1. The southern hemispheric trend reconstructed from firn air reveals that atmospheric abundances of both isomers became significant in the 1960s with accelerating abundances until the late 1970s. The CFC-114 record is similar to that presented in Sturrock et al. (2002) (Fig. S1), who also 


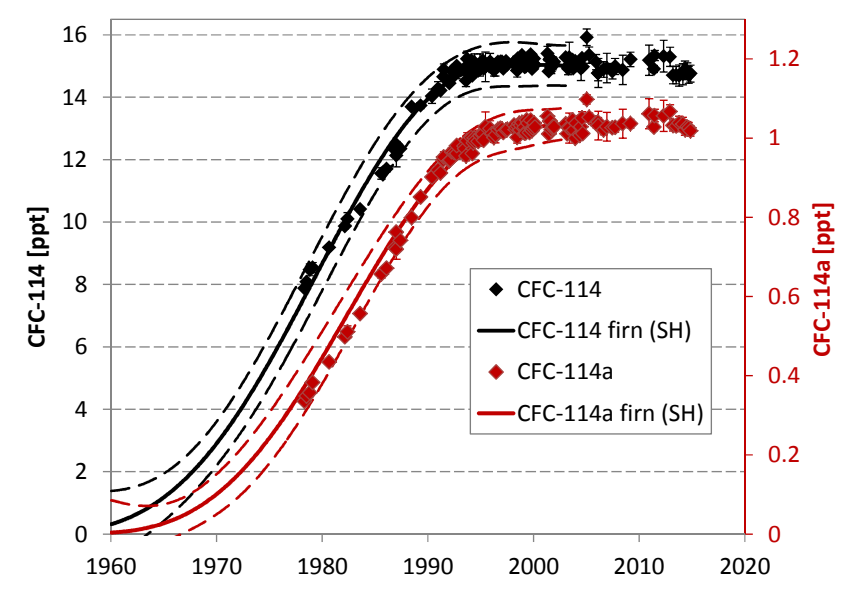

Figure 1. Mixing ratios of CFC-114 and CFC-114a as measured in air samples collected at Cape Grim, Australia, between 1978 and 2014 (diamonds) and derived from two Antarctic firn air profiles (lines). Uncertainties are $1 \sigma$ standard deviations for Cape Grim data and a combination of the former and a firn modelling uncertainty for the latter (shown as dashed lines, see text for further details).

used firn air reconstructions from a different Antarctic site at Law Dome, and an "early day" inverse modelling technique. From both air archives (firn and Cape Grim) we find a further steady increase in abundance from 1978 until the 1990s, followed by a weakening in growth. Also apparent from Fig. 1 is that mixing ratios of CFC-114 stopped increasing around 1993 while those of CFC-114a continued to increase until around 2000. This will be discussed further in Sect. 4.2.

The average atmospheric abundances of CFC-114 and CFC-114a at Cape Grim in 2012 were $15.2 \pm 0.3$ and $1.05 \pm 0.01 \mathrm{ppt}$ respectively. This means that our result agrees well with the combined mixing ratio of $16.33 \mathrm{ppt}$ given in Carpenter et al. (2014) at this point in time (i.e. 2012), with the corresponding calibration scale having been first reported in Prinn et al. (2000). However, our Cape Grim record reveals a steadily increasing contribution from CFC114a starting at $4.2 \%$ in 1978 (Fig. 2) and reaching $6.9 \%$ in 2014. This is confirmed by the ratios observed in the firn airderived record, which shows pre-1978 CFC-114a / CFC-114 ratios of below $4 \%$, although with considerable uncertainties (Fig. 2). Therefore the $\sim 10 \%$ contribution of CFC-114a that has been assumed in Carpenter et al. (2014) and previous WMO/UNEP ozone assessments appears to have been an overestimate. Moreover, the contribution of CFC-114a to the sum of the isomers has been assumed constant in those previous assessments, which is clearly not the case.

CFC-114 is, at the end of our record in 2014, the fourth most abundant CFC in the atmosphere (after CFC-11, CFC12 and CFC-113). Its mixing ratios were, on average, decreasing at $0.01 \mathrm{ppt} \mathrm{yr}^{-1}$ between 2008 and 2014. This is in agreement with Carpenter et al. (2014), who reported an average decrease of $0.01 \mathrm{ppt} \mathrm{yr}^{-1}$ between 2008 and 2012. Al-

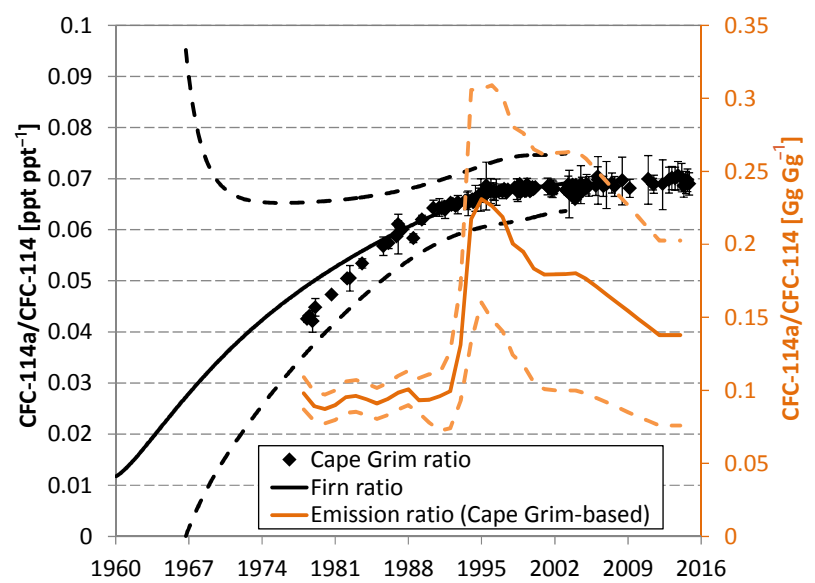

Figure 2. CFC-114a / CFC-114 ratio of mixing ratios at Cape Grim (left axis, black diamonds) and derived from Antarctic firn (left axis, black line), as well as the ratio of their emissions derived from these observations (right axis, orange line). Uncertainties of those ratios are calculated from the uncertainties of mixing ratios (Fig. 1) and emissions (Fig. 3) and using the equation for combining errors in quotients.

though being the fourth most abundant CFC, CFC-114 mixing ratios are substantially lower than the three others (CFC11: 236.3, CFC-12: 524.4 and CFC-113: 73.8 ppt, NOAA global average in 2012, Carpenter et al., 2014). Its isomer CFC-114a is found to be the seventh most abundant CFC in the atmosphere, after CFC-115 and CFC-13, with its growth rate not turning negative until 2008 with a subsequent average decrease of $0.001 \mathrm{ppt} \mathrm{yr}^{-1}$.

\subsection{Global emission estimates}

The atmospheric abundances of CFC-114 and CFC-114a are indicative of their accumulated emissions into the atmosphere. Figure 3 shows the model-based reconstructed global annual emissions of both isomers as derived from the Cape Grim observations. Emissions were already high for both isomers at the beginning of the record in 1978 and peaked between 1986 and 1988 at $18.2 \mathrm{Gg} \mathrm{yr}^{-1}$ (CFC-114) and $1.79 \mathrm{Gg} \mathrm{yr}^{-1}$ (CFC-114a).

Figure 3 shows very similar emission behaviour of both isomers until around 1991. This similarity in the time series of annual emissions is consistent with the use of the isomers as a mixture leading to co-emission. This is even more apparent when looking at the ratio of their emissions (Fig. 2), which remained nearly constant at around $9 \%$ between 1978 and 1991. Such a constant emission ratio may seem counterintuitive at first as the observed ratio of the mixing ratios of the two isomers increases rapidly throughout that period (also shown in Fig. 2). In addition CFC-114a (102 years, Carpenter et al., 2014) has a much shorter atmospheric lifetime as compared to CFC-114 (189 years, SPARC, 2013). These two facts imply that increasingly higher emissions of CFC- 


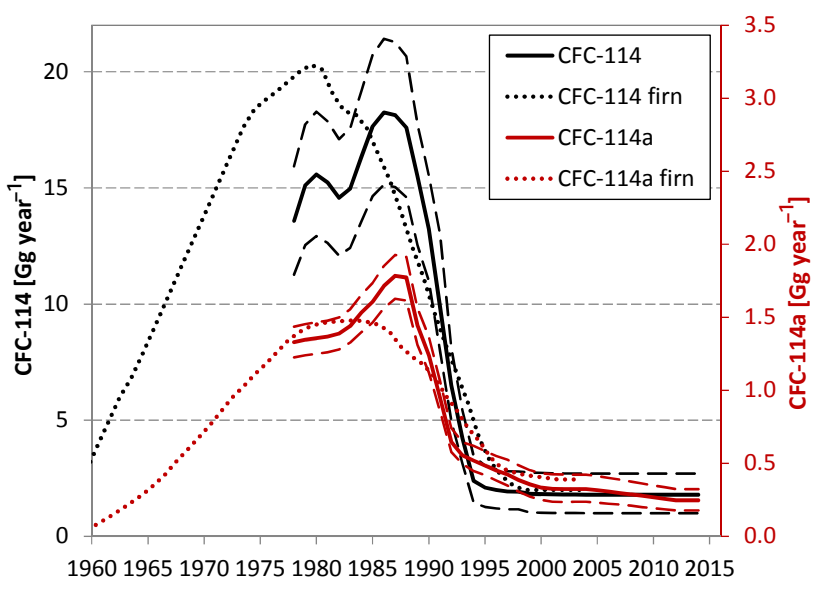

Figure 3. Global emissions of CFC-114 and CFC-114a derived from Cape Grim observations (solid lines) with uncertainties represented by dashed lines. The dotted lines represent emissions derived purely from firn air data.

$114 \mathrm{a}$ would be needed to sustain relative increases (as a percent of the abundance) above those of CFC-114. Both effects (i.e. the increasing ratio of mixing ratios and the lifetime difference) are however compensated in the emissions by the fact that the emission ratio of CFC-114a / CFC-114 between 1978 and 1991 is at about $9 \%$, well above the ratio of the mixing ratios over the same period, which rises from 4.2 to $6.5 \%$. The current assumption of isomeric mixtures emitted to the atmosphere containing $\sim 10 \%$ of CFC- $114 \mathrm{a}$ is consistent with this 13 -year period. However, the implication is that the ratio of pre-1978 emissions must have been significantly more biased towards CFC-114. In other words, emission prior to 1978 must have largely consisted of more than $96 \%$ of CFC-114 and $4 \%$ or less of CFC-114a. This is confirmed by ratio of the mixing ratios in both the Cape Grimbased and the firn-based records (Fig. 2) and could point to a change in manufacturing processes or partly independent source(s).

From 1991 onwards we find a sharp increase of CFC114a emissions relative to those of CFC-114. While emissions of both isomers decrease substantially throughout the 1990s, those of CFC-114a decline much more slowly. The isomeric emission ratio (Fig. 2) only starts to decrease again after CFC-114 emissions stop declining in 1996. In contrast to CFC-114, emissions of CFC-114a continue to decline until 2010. This may seem surprising at first but could perhaps be reconciled by the aforementioned involvement of pure CFC114a in the production of HFC-134a (Banks et al., 1994). Incidentally, abundance of HFC-134a started increasing in the atmosphere in the early 1990s (Montzka et al., 1996b; Oram et al., 1996) as it replaced CFCs predominantly in mobile air conditioning. However, our CFC-114a emission data do not suggest that it is an impurity in all the HFC-134a produced as emissions of the latter continue to increase to date (Carpenter

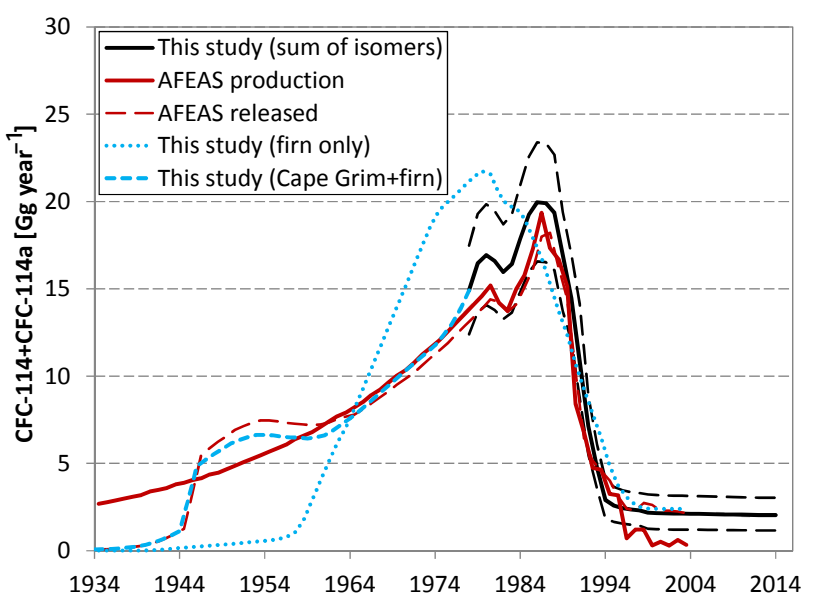

Figure 4. Atmospheric observation-based emissions of the sum of CFC-114 and CFC-114a (black line with black dashed lines representing uncertainty ranges) in comparison with "bottom-up" emissions from the AFEAS inventory. The dotted blue line indicates emissions purely derived from firn air observations while the dashed blue line results from matching the firn-based emissions to the Cape Grim-based emission record in 1978 while not leaving the uncertainty range of the firn-based mixing ratios from Fig. 1.

et al., 2014). CFC-114a is only an intermediate in one of the pathways to synthesise HFC-134a. Our CFC-114a emission data are consistent with two possible scenarios, i.e. (a) emissions of CFC-114a as an impurity in HFC-134a produced via that pathway, as well as (b) emissions at the HFC-134a production level.

We also compare the emission estimates from our "topdown" observation-based approach with the "bottom-up" emissions derived from production and release data from the Alternative Fluorocarbons Environmental Acceptability Study (AFEAS) in Fig. 4. We are only able to compare the sum of both isomers as AFEAS does not distinguish between CFC-114 and CFC-114a. The bottom-up data start much earlier in 1934 but also end earlier in 2003. This is due to reporting companies responding to AFEAS that from 2003 onwards $\mathrm{CFC}-114$ represented a small and diminishing fraction of global $\mathrm{CFC}$ production, which resulted in no further $\mathrm{CFC}$ data being sought or reported (AFEAS, 2009).

In order to be able to compare bottom-up and top-down emissions prior to 1978 an extra emission model run was carried out, matching the firn-derived pre-1978 trend to the Cape Grim-derived record in 1978, which was successful within the constraint from the mixing ratio uncertainty ranges of the firn air record (Fig. 4). The exact temporal shape of this pre-1978 emission record is very uncertain as the uncertainty range in the firn air-derived mixing ratios (Fig. 1) allows a large range of growth rates and therefore emission scenarios. Nevertheless it enables us to conclude that the early part of the AFEAS data, which suggests rapidly increasing emissions to more than $5 \mathrm{Gg} \mathrm{yr}^{-1}$ in the late 1940 s, are incon- 
sistent with our emissions estimates. Emission rates above $5 \mathrm{Gg} \mathrm{yr}^{-1}$, as suggested by AFEAS, are unlikely to have occurred before the mid-1950s. Moreover, a pre-1978 emission maximum is require for CFC-114 (but not for CFC-114a) in order to satisfy both constraints, i.e. (a) matching the emissions of the Cape Grim and firn records in 1978 and (b) not leaving the firn-based uncertainty range. When comparing with existing literature it is notable that the early AFEAS record agrees with the mixing ratio time series of CFC-114 published in Martinerie et al. (2009). This is however mostly because that study used AFEAS emissions as a prior input to the inversion (see also Sect. 3.5), while our records are very similar to the top-down approach-based data set published in Sturrock et al. (2002).

In the overlap period of AFEAS with our Cape Grimbased post-1978 record we find agreement between the two data sets within our uncertainty range apart from a period in the early 1990s. From 1990 to 1993 our emissions are significantly higher than the AFEAS data (Fig. 4). It should however be noted that, while no uncertainties are given in the AFEAS database, there are considerable uncertainties related to bottom-up methods, which are difficult to quantify. This especially applies to the timing of the release to the atmosphere. Differences between the two emission data sets (release data for AFEAS) reach up to $4.5 \mathrm{Gg} \mathrm{yr}^{-1}$ in 1991, but this discrepancy all but disappears after 1993. Both data sets also agree that emissions decreased rapidly and stabilised between 2.0 and $2.3 \mathrm{Gg} \mathrm{yr}^{-1}$ from 2000 onwards, demonstrating the success of the Montreal Protocol. Cumulative emissions from our top-down approach reach $537 \mathrm{Gg}$ in 2003 (uncertainty range from 436 to $627 \mathrm{Gg}$ ) and agree very well with both AFEAS production and release figures between 1934 and 2003, which have been reported at 520 and $511 \mathrm{Gg}$ respectively (AFEAS, 2009). The aforementioned discrepancy in the early part of the record may therefore well originate from pre-1960 production reported by AFEAS, which was not immediately released to the atmosphere. For the post-2003 part, as discussed above and according to AFEAS, a substantial amount of CFC-114 (containing a fraction of CFC-114a) has been believed to be in banks of long-lived equipment. The AFEAS database itself does however not fully reflect this in their emissions as only $8.8 \mathrm{Gg}$ remains "unreleased" to the atmosphere in 2003. If current emissions are from existing equipment, then such a small "bank" is not consistent with current persisting emissions of $1.80 \mathrm{Gg} \mathrm{yr}^{-1}$ (range: 1.0 to $2.7 \mathrm{Gg} \mathrm{yr}^{-1}$ ) of CFC-114 and $0.25 \mathrm{Gg} \mathrm{yr}^{-1}$ (range: 0.18 to $0.32 \mathrm{Gg} \mathrm{yr}^{-1}$ ) of CFC-114a in 2014 , i.e. 11 years after a remainder of $8.8 \mathrm{Gg}$ of banks has been reported. In contrast our cumulative emissions for those 11 years amount to $23 \mathrm{Gg}$ ( 13 to $34 \mathrm{Gg}$ ).

Finally we have also derived emissions purely based on the atmospheric records derived from the firn air data (dotted lines in Figs. 3 and 4). This illustrates the limitations of that methodology when relying on data from only two sites. Atmospheric mixing ratio records fit those from Cape Grim well for the overlap period (Fig. 1). Emission estimates do however strongly depend on the annual growth rates, and thus small discrepancies between the curvature of the firnderived and the Cape Grim-based atmospheric records translate into large changes in the temporal distribution of the estimated emissions. The limited accumulation rate of the two firn sites used here prevents a high temporal resolution of the respective record and results partly in smoothing and partly in a shift of the timing of the emissions. However, the total emissions estimated from the firn record are $530 \mathrm{Gg}$ (range: 505 to $557 \mathrm{Gg}$, period from 1960 to 2003), which agrees very well with those from the mostly Cape Grim-based trend over the same period, as well as the AFEAS data when including emissions reported from 1934 onwards.

\subsection{An interhemispheric gradient case study from CARIBIC}

Most industrialised countries are located in the Northern Hemisphere, which is why trace gases of predominantly anthropogenic origin are known to show interhemispheric gradients (e.g. Carpenter et al., 2014). The results from interhemispheric flights by the CARIBIC Observatory are shown in Fig. 5. Even though we find slightly higher mixing ratios in the Northern Hemisphere, the gradient with latitude is significant neither for CFC-114 nor for CFC-114a (within the $1 \sigma$ measurement uncertainty, i.e. $1.2 \%$ on average for both gases - compared to gradients of 0.8 and $1.0 \%$ for CFC- 114 and CFC-114a respectively when looking at the variability of the atmospheric mixing ratios averaged over both flights). This is consistent with the Cape Grim data that show that global emissions of both of these gases have largely ceased. As our GC-MS analyses revealed no exceptionally high mixing ratios of many other trace gases (e.g. CFC-11, H-1301, HCFC-142b, HFC-134a), we conclude that the sampled air masses are representative of well-mixed mid and upper tropospheric background air during February 2015.

\subsection{Tropospheric samples from Taiwan}

Figure 6 shows the results of our measurements of both isomers on samples collected during a field campaign in southern Taiwan in 2015 (Hengchun site, $22.1^{\circ} \mathrm{N}, 120.7^{\circ} \mathrm{E}$; $7 \mathrm{~m}$ a.s.l.; similar to the 2013 campaign reported by Vollmer et al., 2015). The observed air masses mostly reached the sampling site from China and the Korean Peninsula with no significant influence from Taiwanese industrial regions. Interestingly, we find up to $17 \%$ higher mixing ratios of CFC$114 \mathrm{a}$ when comparing with average mixing ratios observed at Cape Grim between 2012 and 2014. Even samples that show no significantly elevated mixing ratios for several other trace gases that are known to have continuing strong East Asian sources (e.g. HCFC-141b, HFC-227ea) exhibited CFC-114a mixing ratio more than $2 \%$ higher than at Cape Grim. In contrast mixing ratios of CFC-114 are not enhanced signifi- 


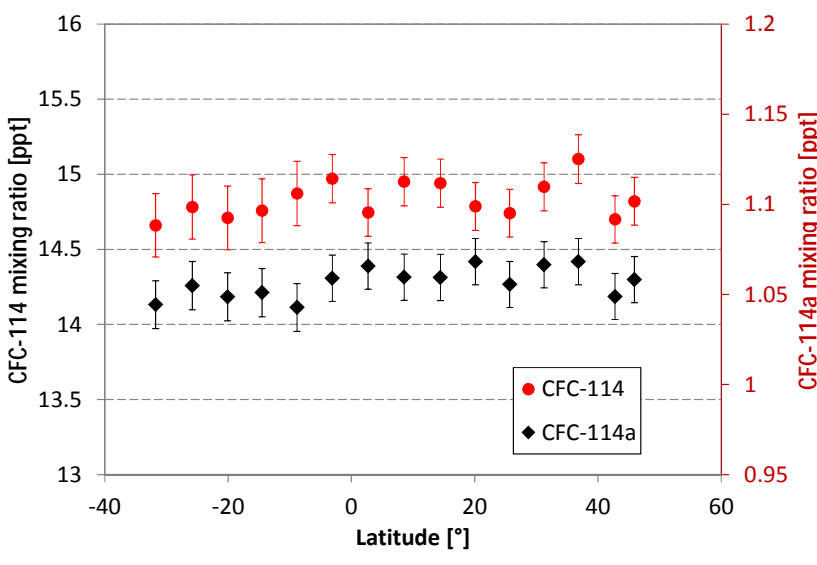

Figure 5. CFC-114 and CFC-114a observations from air samples collected during two interhemispheric aircraft flights from Germany to South Africa and back on 10-11 February 2015. Samples were collected between 8.3 and $11.6 \mathrm{~km}$ altitude and between $45.9^{\circ} \mathrm{N}$ (positive values) and $31.8^{\circ} \mathrm{S}$ (negative).

cantly throughout the campaign confirming that the regional source of CFC-114a is not due to the emission of an isomeric mixture.

HFC-134a during this campaign showed mixing ratios close to background (six samples between 84 and $88 \mathrm{ppt}$ ) as well as enhancements of up to 132 ppt. However, when comparing CFC-114a and HFC-134a we find no significant correlation $\left(R^{2}<0.1\right)$, implying that either (i) most of the regional HFC-134a emissions originate from production pathways not involving CFC-114a and/or (ii) HFC-134a does not contain CFC-114a as an impurity and the latter is only emitted during HFC-134a production. The connection of these regional CFC-114a emissions to HFC-134a production processes is however supported by the fact that we see the biggest enhancements of CFC-115 (between 5 and $10 \%$ above background) and CFC-113a (between 90 and 200\%) in the four samples with the highest CFC-114a mixing ratios - with both these compounds being involved in the same HFC-134a production process (where CFC-113 is isomerised to form CFC-113a, which is then fluorinated to produce CFC-114a, followed by hydrogenolysis to HFC-134a, CFC-115 being a small by-product as a result of overfluorination; Banks et al., 1994). In addition we cannot rule out the possibility of a new onset of CFC-114a emissions as the Taiwan samples were collected after the end of our current Cape Grim record.

\section{Conclusions}

These tropospheric observations provide, for the first time, long-term trends and emissions of both CFC-114 and CFC114a. Based on firn air reconstructions from two Antarctic sites, both isomers had very low atmospheric abundances $(<0.3 \mathrm{ppt})$ before 1960 , which is in agreement with an ear-

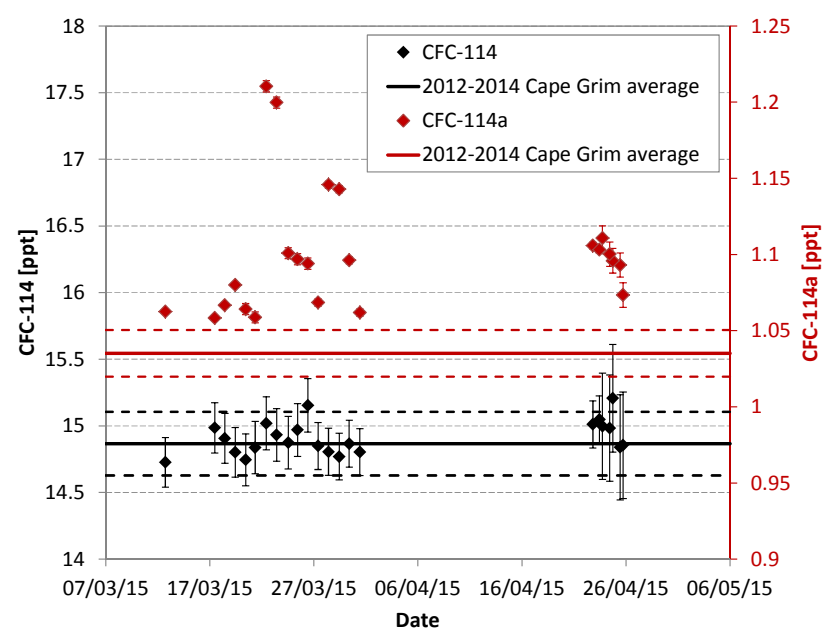

Figure 6. Mixing ratios of CFC-114 and CFC-114a from samples collected during a ground-based campaign near Hengchun, Taiwan, in early 2015 (diamonds) compared to mixing ratios observed at Cape Grim averaged from 2012 to 2014 (lines). Uncertainties (error bars and dashed lines) are $1 \sigma$ standard deviations.

lier study that reported CFC-114 with an undetermined fraction of CFC-114a and was based on a different firn drilling site (Sturrock et al., 2002). We demonstrate the impact of the Montreal Protocol regulations, which banned consumption in developed countries from 1996 (UNEP, 2014), and this is probably the driver of the stabilisation of the global atmospheric mixing ratios of both CFCs. We estimate global cumulative emissions of $514 \mathrm{Gg}$ (range: 415 to $617 \mathrm{Gg}$ ) of CFC-114 and $39 \mathrm{Gg}$ ( 32 to $47 \mathrm{Gg}$ ) of CFC-114a up until 2014, which is largely consistent with industry estimates (AFEAS, 2009) - except for the timing of the early emissions and the remainder in banks after 2003. When using the published global warming potentials (GWPs) of CFC114 (GWP-100: 8590, Hodnebrog et al., 2013) and CFC114a (GWP-100: 6510, Davis et al., 2016), we calculate that these cumulative emissions are equivalent to the emission of 4.67 billion tonnes of $\mathrm{CO}_{2}$. As a result of its higher GWP and its higher abundance CFC-114 is the dominant contributor $(94.5 \%)$ to these $\mathrm{CO}_{2}$-equivalent emissions.

We also find that significant global atmospheric emissions of $1.8 \mathrm{Gg} \mathrm{yr}^{-1}$ (CFC-114, range: 1.0 to $2.7 \mathrm{Gg} \mathrm{yr}^{-1}$ ) and $0.25 \mathrm{Gg} \mathrm{yr}^{-1}$ (CFC-114a, range: 0.18 to $0.32 \mathrm{Gg} \mathrm{yr}^{-1}$ ) persisted until at least 2014, highlighting the need for continued efforts to ensure that these substances eventually disappear from the atmosphere. Further observations are also required to understand the origin of those emissions, especially in the East Asian region. It should however be noted that such emissions are not necessarily in breach of the Montreal Protocol given that CFCs used as intermediates in the production of other compounds (such as HFC-134a) do not have to be reported under that treaty. 
Importantly, CFC-114 and CFC-114a were not always co-produced or co-emitted. This results in time-dependent changes in the ratio of the isomers in atmospheric samples. Thus the use of a simple time-invariant correction (in \%) as assumed in recent assessments of climate change and ozone depletion (e.g. Myhre et al., 2013; Carpenter et al., 2014) is not correct when discussing their abundance changes over time and their impacts on ozone depletion and radiative forcing. Finally, given the differences in trends and emissions we recommend that the two isomers should be reported separately in the future, or that time-dependent speciation factors, such as presented here, should be used to approximate global concentrations of CFC-114 and CFC-114a.

\section{Data availability}

All data have been made publicly available in the supplement.

\section{The Supplement related to this article is available online at doi:10.5194/acp-16-15347-2016-supplement.}

Acknowledgements. Johannes C. Laube received funding from the UK Natural Environment Research Council (Research Fellowship NE/I021918/1) and David E. Oram from the National Centre for Atmospheric Science. The emission modelling work was conducted by Norfazrin Mohd Hanif through a $\mathrm{PhD}$ studentship funded by the Ministry of Education Malaysia (MOE) and Universiti Kebangsaan Malaysia (UKM). Taiwan-related work was also supported by the NERC IOF award NE/J016012/1 and a NERC Studentship to Lauren J. Gooch. We also thank DuPont for providing a CFC-114/CFC-114a mixture, all CARIBIC partners for their contributions and M. J. Newland for constructive discussions. The collection and curation of the Cape Grim air archive is jointly funded by CSIRO and the Bureau of Meteorology (BoM); BoM/CGBAPS staff at Cape Grim were/are largely responsible for the collection of archive samples and UEA flask air samples; the original (mid-1990s) subsampling of the archive for UEA was funded by AFEAS and CSIRO, ongoing subsampling by CSIRO. The Berkner Island drilling was organised and conducted by the British Antarctic Survey with funding from the Natural Environmental Research Council (NERC). Firn air analysis at Dome $\mathrm{C}$ contributed to the European Project for Ice Coring in Antarctica (EPICA), a joint ESF-EC scientific programme (ENV4CT95-0074). The fieldwork at Dome $C$ was also supported by the French Polar Institute (IFRTP) and the ENEA Antarctic Project (Italy). The firn air work was also funded by the CEC programmes: EUK2-CT2001-00116 (CRYOSTAT) and ENV4-CT97-0406 (FIRETRACC).

Edited by: J. B. Burkholder

Reviewed by: three anonymous referees

\section{References}

Alternative Fluorocarbons Environmental Acceptability Study (AFEAS): Production, sales and atmospheric release of fluorocarbons through 1995, AFEAS Administrative Organization, Washington, DC, USA, 1995.

Alternative Fluorocarbons Environmental Acceptability Study (AFEAS): Production and Sales of Fluorocarbons, available at: http://www.afeas.org/overview.php (last access: 4 March 2015), 2009.

Andersen, S. O., Sarma, K. M., and Taddonio, K. N.: Technology transfer for the ozone layer: Lessons for climate change, Earthscan Press, London, UK, 2007.

Baasandorj, M., Feierabend, K. J., and Burkholder, J. B.: Rate coefficients and $\mathrm{ClO}$ radical yields in the reaction of $\mathrm{O}\left({ }^{1} \mathrm{D}\right)$ with $\mathrm{CClF}_{2} \mathrm{CCl}_{2} \mathrm{~F}, \mathrm{CCl}_{3} \mathrm{CF}_{3}, \mathrm{CClF}_{2} \mathrm{CClF}_{2}$, and $\mathrm{CCl}_{2} \mathrm{FCF}_{3}$, Int. J. Chem. Kinet., 43, 1-9, 2011.

Baasandorj, M., Fleming, E. L., Jackman, C. H., and Burkholder, J. B.: $\mathrm{O}\left({ }^{1} \mathrm{D}\right)$ kinetic study of key ozone depleting substances and greenhouse gases, J. Phys. Chem. A, 117, 275-282, doi:10.1021/jp310910f, 2013.

Banks, R. E., Smart, B. E., and Tatlow, J. C. (Eds.): Organofluorine Chemistry: Principles and Commercial Applications, Springer Science+Business Media, New York, USA, 162-165, 1994.

Brenninkmeijer, C. A. M., Crutzen, P., Boumard, F., Dauer, T., Dix, B., Ebinghaus, R., Filippi, D., Fischer, H., Franke, H., Frieß, U., Heintzenberg, J., Helleis, F., Hermann, M., Kock, H. H., Koeppel, C., Lelieveld, J., Leuenberger, M., Martinsson, B. G., Miemczyk, S., Moret, H. P., Nguyen, H. N., Nyfeler, P., Oram, D., O'Sullivan, D., Penkett, S., Platt, U., Pupek, M., Ramonet, M., Randa, B., Reichelt, M., Rhee, T. S., Rohwer, J., Rosenfeld, K., Scharffe, D., Schlager, H., Schumann, U., Slemr, F., Sprung, D., Stock, P., Thaler, R., Valentino, F., van Velthoven, P., Waibel, A., Wandel, A., Waschitschek, K., Wiedensohler, A., Xueref-Remy, I., Zahn, A., Zech, U., and Ziereis, H.: Civil Aircraft for the regular investigation of the atmosphere based on an instrumented container: The new CARIBIC system, Atmos. Chem. Phys., 7, 4953-4976, doi:10.5194/acp-7-4953-2007, 2007.

Buizert, C., Martinerie, P., Petrenko, V. V., Severinghaus, J. P., Trudinger, C. M., Witrant, E., Rosen, J. L., Orsi, A. J., Rubino, M., Etheridge, D. M., Steele, L. P., Hogan, C., Laube, J. C., Sturges, W. T., Levchenko, V. A., Smith, A. M., Levin, I., Conway, T. J., Dlugokencky, E. J., Lang, P. M., Kawamura, K., Jenk, T. M., White, J. W. C., Sowers, T., Schwander, J., and Blunier, T.: Gas transport in firn: multiple-tracer characterisation and model intercomparison for NEEM, Northern Greenland, Atmos. Chem. Phys., 12, 4259-4277, doi:10.5194/acp-12-4259-2012, 2012.

Burkholder, J. B., Mellouki, W., Fleming, E. L., George, C., Heard, D. E., Jackman, C. H., Kurylo, M. J., Orkin, V. L., Swartz, W. H., and Wallington, T. J.: Evaluation of atmospheric loss processes, in: SPARC. Lifetimes of Stratospheric Ozone-Depleting Substances, Their Replacements, and Related Species, edited by: Ko, M. K. W., Newman, P. A., Reimann, S., and Strahan, S. E., World Climate Research Program, Geneva, Switzerland, 2013.

Carpenter, L. J., Reimann, S., Burkholder, J. B., Clerbaux, C., Hall, B. D., Hossaini, R., Laube, J. C., and Yvon-Lewis, S. A.: Ozonedepleting substances (ODSs) and other gases of interest to the Montreal Protocol, in: Scientific Assessment of Ozone Depletion: 2014, Global Ozone Research and Monitoring Project - 
Rep. No. 55, Chap. 1, World Meteorol. Organ., Geneva, Switzerland, 2014.

Chan, C. Y., Tang, J. H., Li, Y. S., and Chan, L. Y.: Mixing ratios and sources of halocarbons in urban, semi-urban and rural sites of the Pearl River Delta, South China, Atmos. Environ., 40, 7331-7345, 2006.

Chen, L., Makide, Y., and Tominaga, T.: Determination of 1,2dichlorotetrafluoroethane (CFC-114) concentration in the atmosphere, Chem. Lett., 3, 571-574, 1994.

Chen, N. H. and Othmer, D. F.: New generalized equation for gas diffusion coefficient, J. Chem. Eng. Data, 7, 37-41, doi:10.1021/je60012a011, 1962.

Davis, M. E., Bernard, F., McGillen, M. R., Fleming, E. L., and Burkholder, J. B.: UV and infrared absorption spectra, atmospheric lifetimes, and ozone depletion and global warming potentials for $\mathrm{CCl}_{2} \mathrm{FCCl}_{2} \mathrm{~F}$ (CFC-112), $\mathrm{CCl}_{3} \mathrm{CClF}_{2}(\mathrm{CFC}$ 112a), $\mathrm{CCl}_{3} \mathrm{CF}_{3}$ (CFC-113a), and $\mathrm{CCl}_{2} \mathrm{FCF}_{3}$ (CFC-114a), Atmos. Chem. Phys., 16, 8043-8052, doi:10.5194/acp-16-80432016, 2016.

Farman, J. C., Gardiner, B. G., and Shanklin, J. D.: Large losses of total ozone in Antarctica reveal seasonal $\mathrm{ClO}_{x} / \mathrm{NO}_{x}$ interaction, Nature, 315, 207-210, 1985

Fisher, D. A. and Midgley, P. M.: The production and release to the atmosphere of CFCs 113, 114 and 115, Atmos. Environ., 27A, 271-276, 1993.

Fraser, P. J., Hyson, P., Rasmussen, R. A., Crawford, A. J., and Khalil, M. A. K.: Methane, carbon monoxide and methylchloroform in the southern hemisphere, J. Atmos. Chem., 4, 3-42, 1986.

Fraser, P. J., Oram, D. E., Reeves, C. E., Penkett, S. A., and McCulloch, A.: Southern hemispheric halon trends (1978-1998) and global emissions, J.Geophys. Res., 104, 15985-15999, 1999.

Fuller, E. N., Schettler, P. D., and Giddings, J. C.: A new method for prediction of binary gas-phase diffusion coefficients, Ind. Eng. Chem., 58, 19-27, doi:10.1021/ie50677a007, 1966.

Hodnebrog, O., Etminan, M., Fuglestvedt, J. S., Marston, G., Myhre, G., Nielsen, C. J., Shine, K. P., and Wallington, T. J.: Global warming potentials and radiative efficiencies of halocarbons and related compounds: A comprehensive review, Rev. Geophys., 51, 300-378, 2013.

Kloss, C., Newland, M. J., Oram, D. E., Fraser, P. J., Brenninkmeijer, C. A. M., Röckmann, T., and Laube, J. C.: Atmospheric abundances, trends and emissions of CFC-216ba, CFC-216ca and HCFC-225ca, Atmosphere, 5, 420-434, 2014.

Laube, J. C., Martinerie, P., Witrant, E., Blunier, T., Schwander, J., Brenninkmeijer, C. A. M., Schuck, T. J., Bolder, M., Röckmann, T., van der Veen, C., Bönisch, H., Engel, A., Mills, G. P., Newland, M. J., Oram, D. E., Reeves, C. E., and Sturges, W. T.: Accelerating growth of HFC-227ea $(1,1,1,2,3,3,3$-heptafluoropropane) in the atmosphere, Atmos. Chem. Phys., 10, 5903-5910, doi:10.5194/acp-10-5903-2010, 2010.

Laube, J. C., Hogan, C., Newland, M. J., Mani, F. S., Fraser, P. J., Brenninkmeijer, C. A. M., Martinerie, P., Oram, D. E., Röckmann, T., Schwander, J., Witrant, E., Mills, G. P., Reeves, C. E., and Sturges, W. T.: Distributions, long term trends and emissions of four perfluorocarbons in remote parts of the atmosphere and firn air, Atmos. Chem. Phys., 12, 4081-4090, doi:10.5194/acp12-4081-2012, 2012.
Laube, J. C., Keil, A., Bönisch, H., Engel, A., Röckmann, T., Volk, C. M., and Sturges, W. T.: Observation-based assessment of stratospheric fractional release, lifetimes, and ozone depletion potentials of ten important source gases, Atmos. Chem. Phys., 13, 2779-2791, doi:10.5194/acp-13-2779-2013, 2013.

Laube, J. C., Newland, M. J., Hogan, C., Brenninkmeijer, C. A. M., Fraser, P. J., Martinerie, P., Oram, D. E., Reeves, C. E., Röckmann, T., Schwander, J., Witrant, E., and Sturges, W. T.: Newly detected ozone depleting substances in the atmosphere, Nat. Geosci., 7, 266-269, 2014.

Lee, J. M.: Determination of stratospheric lifetimes of HCFCs and other halogenated hydrocarbons from balloon-borne profile measurements, PhD Thesis, University of East Anglia, UK, 1994.

Marsh, K. N., Abramson, A., Ambrose, D., Morton, D. W., Nikitin, E., Tsonopoulos, C., and Young, C. L.: Vapor-liquid critical properties of elements and compounds, 10. Organic compounds containing halogens, J. Chem. Eng. Data, 52, 1509-1538, doi:10.1021/je700336g, 2007.

Martinerie, P., Nourtier-Mazauric, E., Barnola, J.-M., Sturges, W. T., Worton, D. R., Atlas, E., Gohar, L. K., Shine, K. P., and Brasseur, G. P.: Long-lived halocarbon trends and budgets from atmospheric chemistry modelling constrained with measurements in polar firn, Atmos. Chem. Phys., 9, 3911-3934, doi:10.5194/acp-9-3911-2009, 2009.

Matsunaga, N., Hori, M., and Nagashima, A.: Mutual diffusion coefficients of halogenated-hydrocarbon refrigerant-air systems, High Temperatures High Pressures, 25, 63-70, 1993.

McCulloch, A., Midgley, P. M., and Fisher, D. A.: Distribution of emissions of chlorofluorocarbons (CFCs) 11, 12, 113, 114 and 115 among reporting and nonreporting countries in 1986, Atmos. Environ., 28, 2567-2582,1994.

Montzka, S. A., Butler, J. H., Myers, R. C., Thompson, T. M., Swanson, T. H., Clarke, A. D., Lock, L. T., and Elkins, J. W.: Decline in tropospheric abundance of halogen from halocarbons: implications for stratospheric ozone depletion, Science, 31, 1318-1322, 1996a.

Montzka, S. A., Myers, R. C., Butler, J. H., Elkins, J. W., Lock, L. T., Clarke, A. D., and Goldstein, A. H.: Observations of HFC$134 \mathrm{a}$ in the remote troposphere, Geophys. Res. Lett., 23, 169172, doi:10.1029/95GL03590, 1996b.

Montzka, S. A., Reimann, S., Engel, A., Krüger, K., O’Doherty, S., Sturges, W. T., Blake, D., Dorf, M., Fraser, P., Froidevaux, L., Jucks, K., Kreher, K., Kurylo, M. J. Mellouki, A., Miller, J., Nielsen, O.-J., Orkin, V. L., Prinn, R. G., Rhew, R., Santee, M. L., Stohl, A., and Verdonik, D.: Ozone-depleting substances (ODSs) and related chemicals, in: World Meteorological Organization Global Ozone Research and Monitoring Project-Report No. 52, Scientific Assessment of Ozone Depletion: 2010, WMO, Geneva, Switzerland, 2010.

Myhre, G., Shindell, D., Bréon, F.-M., Collins, W., Fuglestvedt, J., Huang, J., Koch, D., Lamarque, J.-F., Lee, D., Mendoza, B., Nakajima, T., Robock, A., Stephens, G., Takemura, T., and Zhang, H.: Anthropogenic and natural radiative forcing, in: Climate Change 2013: The Physical Science Basis, Contribution of Working Group I to the Fifth Assessment Report of the Intergovernmental Panel on Climate Change, edited by: Stocker, T. F., Qin, D., Plattner, G.-K., Tignor, M., Allen, S. K., Boschung, J., Nauels, A., Xia, Y., Bex, V., and Midgley, P. M., Cambridge University Press, Cambridge, UK and New York, NY, USA, 2013. 
Newland, M. J., Reeves, C. E., Oram, D. E., Laube, J. C., Sturges, W. T., Hogan, C., Begley, P., and Fraser, P. J.: Southern hemispheric halon trends and global halon emissions, 1978-2011, Atmos. Chem. Phys., 13, 5551-5565, doi:10.5194/acp-13-55512013, 2013.

Oram, D. E.: Trends of long-lived anthropogenic halocarbons in the southern hemisphere and model calculations of global emissions, PhD Thesis, University of East Anglia, UK, 1999.

Oram, D. E., Reeves, C. E., Sturges, W. T., Penkett, S. A., Fraser, P. J., and Langenfelds, R. L.: Recent tropospheric growth rate and distribution of HFC-134a $\left(\mathrm{CF}_{3} \mathrm{CH}_{2} \mathrm{~F}\right)$, Geophys. Res. Lett., 23, 1949-1952, 1996.

Oram, D. E., Mani, F. S., Laube, J. C., Newland, M. J., Reeves, C. E., Sturges, W. T., Penkett, S. A., Brenninkmeijer, C. A. M., Röckmann, T., and Fraser, P. J.: Long-term tropospheric trend of octafluorocyclobutane (c- $\mathrm{C}_{4} \mathrm{~F}_{8}$ or PFC-318), Atmos. Chem. Phys., 12, 261-269, doi:10.5194/acp-12-261-2012, 2012.

Prinn, R. G., Weiss, R. F., Fraser, P. J., Simmonds, P. G., Cunnold, D. M., Alyea, F. N., O’Doherty, S., Salameh, P., Miller, B. R., Huang, J., Wang, R. H. J., Hartley, D. E., Harth, C., Steele, L. P., Sturrock, G., Midgley, P. M., and McCulloch, A.: A history of chemically and radiatively important gases in air deduced from ALE/GAGE/AGAGE, J. Geophys. Res., 105, 1775117792, doi:10.1029/2000JD900141, 2000.

Reeves, C. E., Sturges, W. T., Sturrock, G. A., Preston, K., Oram, D. E., Schwander, J., Mulvaney, R., Barnola, J.-M., and Chappellaz, J.: Trends of halon gases in polar firn air: implications for their emission distributions, Atmos. Chem. Phys., 5, 2055-2064, doi:10.5194/acp-5-2055-2005, 2005.

Reimann, S., Schaub, D., Stemmler, K., Folini, D., Hill, M., Hofer, P., Buchmann, B., Simmonds, P. G., Greally, B. R., and O'Doherty, S.: Halogenated greenhouse gases at the Swiss high alpine site of Jungfraujoch (3580 m a.s.1.): Continuous measurements and their use for regional European source allocation, J. Geophys. Res., 109, D05307, doi:10.1029/2003JD003923, 2004.

Rigby, M., Prinn, R. G., O’Doherty, S., Montzka, S. A., McCulloch, A., Harth, C. M., Mühle, J., Salameh, P. K., Weiss, R. F., Young, D., Simmonds, P. G., Hall, B. D., Dutton, G. S., Nance, D., Mondeel, D. J., Elkins, J. W., Krummel, P. B., Steele, L. P., and Fraser, P. J.: Re-evaluation of the lifetimes of the major CFCs and $\mathrm{CH}_{3} \mathrm{CCl}_{3}$ using atmospheric trends, Atmos. Chem. Phys., 13, 2691-2702, doi:10.5194/acp-13-2691-2013, 2013.

Rommelaere, V., Arnaud, L., and Barnola, J.: Reconstructing recent atmospheric trace gas concentrations from polar firn and bubbly ice data by inverse methods, J. Geophys. Res., 102D, 3006930083, 1997.

Rowland, F. S. and Molina, M. J.: Chlorofluoromethanes in the environment, Rev. Geophys. Space, 13, 1-35, 1975.

Sander, S. P., Friedl, R. R., Abbatt, J. P. D., Barker, J. R., Burkholder, J. B., Golden, D. M., Kolb, C. E., Kurylo, M. J., Moortgat, G. K., Wine, P. H., Huie, R. E., and Orkin, V. L.: Chemical kinetics and photochemical data for use in atmospheric studies, evaluation number 17, JPL Publ. 10-6, 4G-33, Pasadena, USA, 2011.
Simon, P. C., Gillotay, D., Vanlaethem-Meuree, N., and Wisemberg, J.: Temperature dependence of ultraviolet absorption crosssections of chlorofluoroethanes, Ann. Geophys., 6, 239-248, 1988.

SPARC: Report on the lifetimes of stratospheric ozone-depleting substances, their replacements, and related species, edited by: Ko, M., Newman, P., Reimann, S., and Strahan, S., SPARC Report No. 6, WCRP-15/2013, Geneva, Switzerland, 2013.

Sturges, W. T., Oram, D. E., Laube, J. C., Reeves, C. E., Newland, M. J., Hogan, C., Martinerie, P., Witrant, E., Brenninkmeijer, C. A. M., Schuck, T. J., and Fraser, P. J.: Emissions halted of the potent greenhouse gas $\mathrm{SF}_{5} \mathrm{CF}_{3}$, Atmos. Chem. Phys., 12, 3653 3658, doi:10.5194/acp-12-3653-2012, 2012.

Sturrock, G. A., Etheridge, D. M., Trudinger, C. M., Fraser, P. J., and Smith, A. M.: Atmospheric histories of halocarbons from analysis of Antarctic firn air: Major Montreal Protocol species, J. Geophys. Res., 107, 4765, doi:10.1029/2002JD002548, 2002.

Tong, H. Y. and Karasek F. W.: Flame ionization detector response factors for compound classes in quantitative analysis of complex organic mixtures, Anal. Chem., 56, 2124-2128, 1984.

UNEP: Status of Ratification, List of Parties Categorised as Operating under Article 5 Paragraph 1 of the Montreal Protocol, available at: http://ozone.unep.org (last access: 27 May 2016), 2014.

Vollmer, M. K., Miller, B. R., Rigby, M., Reimann, S., Mühle, J., Krummel, P. B., O’Doherty, S., Kim, J., Rhee, T. S., Weiss, R. F., Fraser, P. J., Simmonds, P. G., Salameh, P. K., Harth, C. M., Wang, R. H. J., Steele, L. P., Young, D., Lunder, C. R., Hermansen, O., Ivy, D., Arnold, T., Schmidbauer, N., Kim, K.R., Greally, B. R., Hill, M., Leist, M., Wenger, A., and Prinn, R. G.: Atmospheric histories and global emissions of the anthropogenic hydrofluorocarbons HFC-365mfc, HFC245fa, HFC-227ea, and HFC-236fa, J. Geophys. Res., 116, D08304, doi:10.1029/2010JD015309, 2011.

Vollmer, M. K., Rigby, M., Laube, J. C., Henne, S., Rhee, T. S., Gooch, L. J., Wenger, A., Young, D., Steele, L. P., Langenfelds, R. L., Brenninkmeijer, C. A. M., Wang, J. L., Ou-Yang, C. F., Wyss, S. A., Hill, M., Oram, D. E., Krummel, P. B., Schoenenberger, F., Zellweger, C., Fraser, P. J., Sturges, W. T., O’Doherty, S., and Reimann, S.: Abrupt reversal in emissions and atmospheric abundance of HCFC-133a $\left(\mathrm{CF}_{3} \mathrm{CH}_{2} \mathrm{Cl}\right)$, Geophys. Res. Lett., 42, 8702-8710, doi:10.1002/2015GL065846, 2015.

Witrant, E. and Martinerie, P.: Input estimation from sparse measurements in LPV systems and isotopic ratios in polar firns, in: Proceedings of the 5th IFAC Symposium on System Structure and Control, Grenoble, France, 4-6 February 2013, 46, 654-659, doi:10.3182/20130204-3-FR-2033.00201, 2013.

Witrant, E., Martinerie, P., Hogan, C., Laube, J. C., Kawamura, K., Capron, E., Montzka, S. A., Dlugokencky, E. J., Etheridge, D., Blunier, T., and Sturges, W. T.: A new multi-gas constrained model of trace gas non-homogeneous transport in firn: evaluation and behaviour at eleven polar sites, Atmos. Chem. Phys., 12, 11465-11483, doi:10.5194/acp-12-11465-2012, 2012. 